\title{
Longitudinal, seasonal and solar cycle variation in lunar tide influence on the equatorial electrojet
}

\author{
Endawoke Yizengaw $^{1}$ and Brett A. Carter ${ }^{2}$ \\ ${ }^{1}$ Institute for Scientific Research, Boston College, Chestnut Hill, Massachusetts, USA \\ ${ }^{2}$ SPACE Research Centre, RMIT University, Melbourne, Victoria, Australia \\ Correspondence to: Endawoke Yizengaw (kassie@bc.edu)
}

Received: 30 August 2016 - Revised: 17 January 2017 - Accepted: 10 March 2017 - Published: 5 April 2017

\begin{abstract}
It has been well documented that the lunar tidal waves can modulate the ionospheric electrodynamics and create a visible influence on the equatorial electrojet (EEJ). The lunar tide influence gets intensified around noon, primarily during new and full Moon periods. However, the longitudinal, seasonal and solar cycle variability in the lunar tide influence on ionospheric current systems is not well understood yet. In order to investigate this, 17 years (1998-2014) of extensive magnetometer observations at four longitudinal sectors (western American, western and eastern African, and Asian) have been analyzed. All observations performed during magnetically active periods $\left(K_{\mathrm{p}}>3\right)$ have been excluded for this study to eliminate storm contributions to the geomagnetic field variation at the geomagnetic equator. This study's quantitative analysis revealed significant longitudinal, seasonal and solar cycle dependence of the lunar tide influence on the equatorial electrojet.
\end{abstract}

Keywords. Ionosphere (electric fields and currents; equatorial ionosphere; ionosphere-atmosphere interactions)

\section{Introduction}

The magnitude of the lunar tidal force, which is generated by gravitational attraction between the Earth and Moon, varies depending on the position of the Moon, Earth and Sun, where the lunar tidal forces become nearly in phase or out of phase with the gravitational solar tide. Approximately twice a month, around new and full Moon when the Sun, Moon and Earth form a line, the lunar tidal force becomes stronger and reaches its maximum peak due to the additive contribution of the gravitational solar tide. On the other hand, when the Moon is at first or third quarter, which is when the Sun and
Moon are at right angles to each other, the gravitational solar tide partially cancels out the lunar tide and produces low-tomoderate magnitude lunar tides. Therefore, during each lunar month, two sets of maximum (spring tides) and two sets of minimum (neap tides) lunar tidal forces occur (Thurman, 1994).

The existence of lunar tides in the $\mathrm{E}$ region and its impact on the E-region dynamo system have been demonstrated in a variety of ways (Matsushita, 1967, 1973). Using a linear theory, Sawada (1956) has shown that the lunar tide, which is predominantly semi-diurnal, propagates from the surface up into the $\mathrm{E}$ region of the ionosphere, where it modulates the equatorial electrodynamics and produces a significant influence on the ionospheric current system. This implies that the lunar semi-diurnal tide can generate an electrostatic field through dynamo action that may modulate the diurnal EEJ strength (e.g., Tarpley, 1970; Chau et al., 2009; Fejer et al., 2010, 2011; Lühr et al., 2012), which then is conveyed to the $\mathrm{F}$ region along the magnetic field lines and causes semidiurnal variations in F-region parameters such as $E \times B$ drifts (e.g., Rastogi, 1968; Fejer et al., 2011).

Since its first recognition (Bartels and Johnston, 1940) and later in the 60s and 70s (e.g., Rastogi, 1968; Rastogi and Trivedi, 1970; Tarpley and Balsley, 1972), the lunar tide appears to be one of atmospheric tides with a significant influence on the EEJ (e.g., Fejer et al., 2010, 2011). Ground- and space-based magnetometer observations have been used to detect the lunar tide influence on the EEJ. However, due to the limitation of ground-based data coverage, comprehensive global studies about the lunar tide influence on ionospheric current systems primarily in terms of longitudinal, solar cycle and local time dependence, have not been fully realized yet. Rastogi and Trivedi (1970), using limited data obtained 
during the International Geophysical Year and the International Geophysical Cooperation (IGY-IGC) period (on average, 1 year of data for each station), reported significant longitudinal variability in the lunar tide. Stening (2011), using magnetometer data, also reported about the relationship between sudden stratospheric warmings (SSWs) and large lunar tide amplitude at different longitudes. Recently, Lühr et al. (2012), using magnetometer observations onboard the CHAMP satellite, reported longitudinal and solar cycle variability in lunar tidal wave amplitudes and found no significant longitudinal variability in the lunar tidal wave impact on the EEJ. However, they recommended further investigations using ground-based observations, as CHAMP data require 131 days to sample all local times, which may not be suitable for analyzing the longitudinal variability in lunar tidal waves.

In order to have a more complete understanding of the longitudinal, seasonal and solar cycle variability in the lunar tide influence on the EEJ, 17 years (1998-2014) of extensive ground-based magnetometer observations at four longitudinal sectors (western American, western and eastern African, and Asian) in the vicinity of the geomagnetic equator have been analyzed. This provides a good opportunity to investigate the solar cycle variability in the lunar tide at different longitudes, for the first time, using ground-based observations. Our results clearly show significant lunar tide variations that have strong longitudinal, seasonal and solar cycle dependence.

\section{Data analysis}

The EEJ produces a strong enhancement in the $\mathrm{H}$-component magnetic field measured by magnetometers located within $\pm 3^{\circ}$ of the magnetic equator (e.g., Anderson et al., 2002; Yizengaw et al., 2014). The strength of the EEJ has been determined at different longitudes using magnetometers located in the American, African, and Asian sectors. The magnetometer stations used for this study include Huancayo $\left(12.05^{\circ} \mathrm{S}, 75.3^{\circ} \mathrm{W} ; 0.62^{\circ} \mathrm{N}\right.$ magnetic) in the American sector, Mbour $\left(14.38^{\circ} \mathrm{N}, 16.97^{\circ} \mathrm{W} ; 2.03^{\circ} \mathrm{N}\right.$ magnetic) in the western African sector, Addis Ababa $\left(9.0^{\circ} \mathrm{N}, 38.8^{\circ} \mathrm{E} ; 0.9^{\circ} \mathrm{N}\right.$ magnetic) in the eastern African sector, and Davao $\left(7.06^{\circ} \mathrm{N}\right.$, $125.6^{\circ} \mathrm{E} ; 0.96^{\circ} \mathrm{N}$ magnetic) in the Asian region, as shown in Fig. 1. These stations were among those few equatorial sites that have data records for quite a long time. In principle, measuring the magnetic perturbation using equatorial magnetometers could provide a direct measure of the EEJ. However, ground magnetometers respond to all currents within their field of view. Thus, equatorial stations respond primarily to the EEJ, which is directly overhead, but also to the ring current and the global solar quiet, $S_{\mathrm{q}}$, current system. In order to isolate the lunar tidal effect, the ring current and global $S_{\mathrm{q}}$ dynamo contributions to the $\mathrm{H}$ component should then be removed. This can be done by using either a pair of magne- tometers located at the magnetic equator and off the equator (6-9 $9^{\circ}$ geomagnetic) or using the technique described below for the case of single stations observations.

For this study we have excluded the full dataset of days with $K_{\mathrm{p}}>3$, hence eliminating any EEJ variation associated with magnetic activity. Similarly, to obtain the average $S_{\mathrm{q}}$ current variation and the secular baseline level for a given period we tightened the selection requirement to use only days with $K_{\mathrm{p}}<2$. In order to have long-term data coverage, especially in the African sector, a single station observation has been used. Therefore, to identify the lunar tide influence on the EEJ, we applied the following procedures to the $\mathrm{H}$ component field observed at the geomagnetic equator.

The first procedure is to identify the daily variation in the magnetic field, which is its deviation from the monthly averaged background value (zero level). The monthly averaged background geomagnetic field value, which is also approximately equal to the secular field level, is calculated by taking the nightside (22:00-02:00 LT) average of the quiet days' $\left(K_{\mathrm{p}}<2\right)$ magnetic field readings of a given month. The daily variations in the magnetic field are then identified by subtracting the monthly average background magnetic field values. This procedure also removes secular field values from the daily $\mathrm{H}$-component field.

The next step is removing magnetic variations associated with $S_{\mathrm{q}}$ and ring current contributions. The diurnal component, which is mainly but not solely due to the $S_{\mathrm{q}}$ current system, should also be removed. This can be accomplished by including data from quiet days of the month $\left(K_{\mathrm{p}}<2\right)$ and determining an average value for every $30 \mathrm{~min}$ interval. The 48 distinct values of the day can then be interpolated to a time resolution of $1 \mathrm{~min}$ and subtracted from the daily data within the given month. This procedure also removes the magnetic field variation associated with the solar diurnal tide, which is described below. The ring current contribution to the magnetic field disturbance has also been removed by subtracting the Dst index. We used one minute resolution of the revised Dst index provided by the US Geological Survey.

The geomagnetic field can also be modulated by the geomagnetic solar tide, which is different from the gravitational solar tide mentioned before. The ionospheric currents that are associated with the geomagnetic solar tide are generated by two kinds of atmospheric solar tides, namely the solar diurnal tide (forcing from below due to the local solar heating in the lower thermosphere) (e.g., Tarpley, 1970) and the solar semidiurnal tide (thermal forcing due to the absorption of solar radiation in the troposphere and stratosphere and subsequent propagation upward to the ionosphere) (e.g., Richmond and Roble, 1987). Magnetic variations associated with the first solar tide type may be removed by subtracting $S_{\mathrm{q}}$ current contributions, described above. Therefore, the semi-diurnal geomagnetic solar tide component, which varies with season and is believed to be almost twice that of the lunar tide magnitude, can then be removed by subtracting the 90-day average value (Yamazaki et al., 2011). 


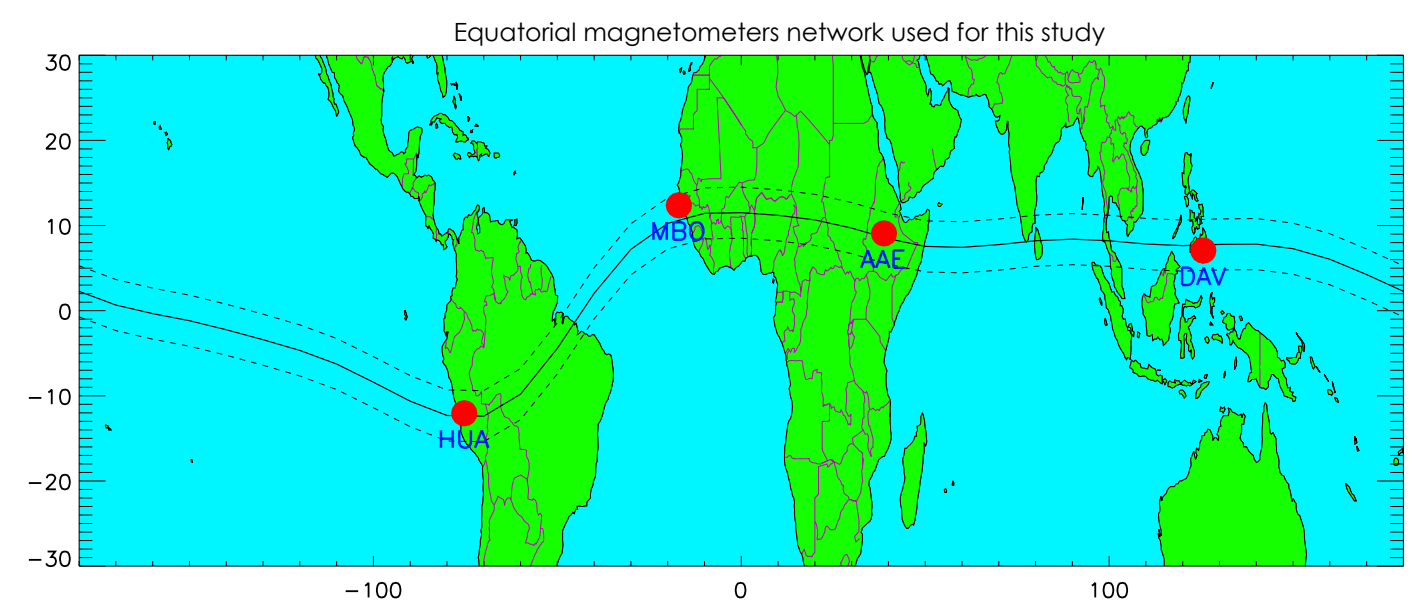

Figure 1. Geographic location of the ground-based magnetometers used for this study. The solid horizontal line depicts the geomagnetic equator, and the two dashed lines indicate the equatorial electrojet region.

The final significant factor that needs to be removed is the noncyclic change, which may be the result of slow magnetospheric recovery on quiet days from earlier geomagnetic disturbances. Although the noncyclic changes are generally negligibly small since the Dst is already removed, we defined the noncyclic change as the difference between the beginning and end values of the day (Matsushita and Campbell, 1972). The value of noncyclic change is then subtracted from the residual on a daily basis. After removing all the contributions mentioned above, the residual magnetic variations may still contain the components of variations due to lunar tide and ionospheric disturbance dynamo. Since this study considers only geomagnetic quiet days, the variation due to ionospheric disturbance dynamo effects is insignificant. Finally, the residual $\mathrm{H}$-component magnetic field variations are due to lunar tidal force, and are averaged and arranged as a function of lunar age.

\section{Results and discussion}

A variety of evidence suggests that the magnitude and direction of the EEJ can be modulated by lunar tides (e.g., Fejer et al., 2010; Yamazaki et al., 2012; Lühr et al., 2012). The stronger lunar tide, which occurs during full and new Moon periods, produces stronger EEJ modulation as a function of local time and lunar age. The question is, how does the lunar tide modulate the EEJ current at the E region? The lunar tide is simply due to the gravitational attraction between the Moon and Earth that slightly modifies the pressure and temperature of the lower atmosphere, and the effects propagate upward in a tidal wave form to the $\mathrm{E}$ region and modulate the electrodynamics (e.g. Chapman and Lindzen, 1970) in the same way the upward-propagating gravity waves modulate the E-region dynamo. Thus, to determine the effects of the semi-diurnal lunar tide, the abovementioned residuals are arranged and averaged as a function of lunar age as shown in Fig. 2 bottom panel. The figure shows that the normal diurnal EEJ currents that we observed from ground-based magnetometers in the vicinity of the geomagnetic equator are indeed modulated by semi-diurnal lunar tides.

The bottom panel in Fig. 2 shows a typical example of 5-year (2005-2009) average lunar tide structure on the EEJ observed at Huancayo in Peru during the fall season (September-November) of each year. Since we have excluded data from disturbed days, significant data gaps have been observed when we used only 1 or 2 years of data; thus, to make sure no data gaps exist in our analysis, we averaged 5 years of data during solar minimum period. Figure 2 clearly shows semi-diurnal variability in the EEJ with maximum peaks during new and full Moon periods. These maximum peaks do not appear at the same lunar age for every solar local time, and instead they show a clear shift which is associated with the motion of the Moon that leads to the formation of the phase change. Lühr et al. (2012) fitted a regression line to the phase values that were determined independently for each local time hour and found that the semidiurnal tidal wave crest appears to be delayed by $1-2 \mathrm{~h}$ from the motion of the Moon.

The magnetic variations at the geomagnetic equator associated with the lunar tide do follow the Chapman's phase law (Chapman, 1919). Although the lunar tidal force has diurnal and semi-diurnal impacts on magnetic variations, the semidiurnal ( $12 \mathrm{~h}$ for lunar day or 14 days for lunar month) lunar tide component is the dominant harmonic (Winch, 1970). Since the diurnal lunar tide impact on the magnetic variation is very weak, in this study we focus on semi-diurnal lunar tide impacts on the EEJ. Thus, the semi-diurnal lunar tide $\left(L_{2}\right)$ component at a fixed local noon time can be represented mathematically as

$L_{2}=A \sin (2 \tau)+B \cos (2 \tau)$, 


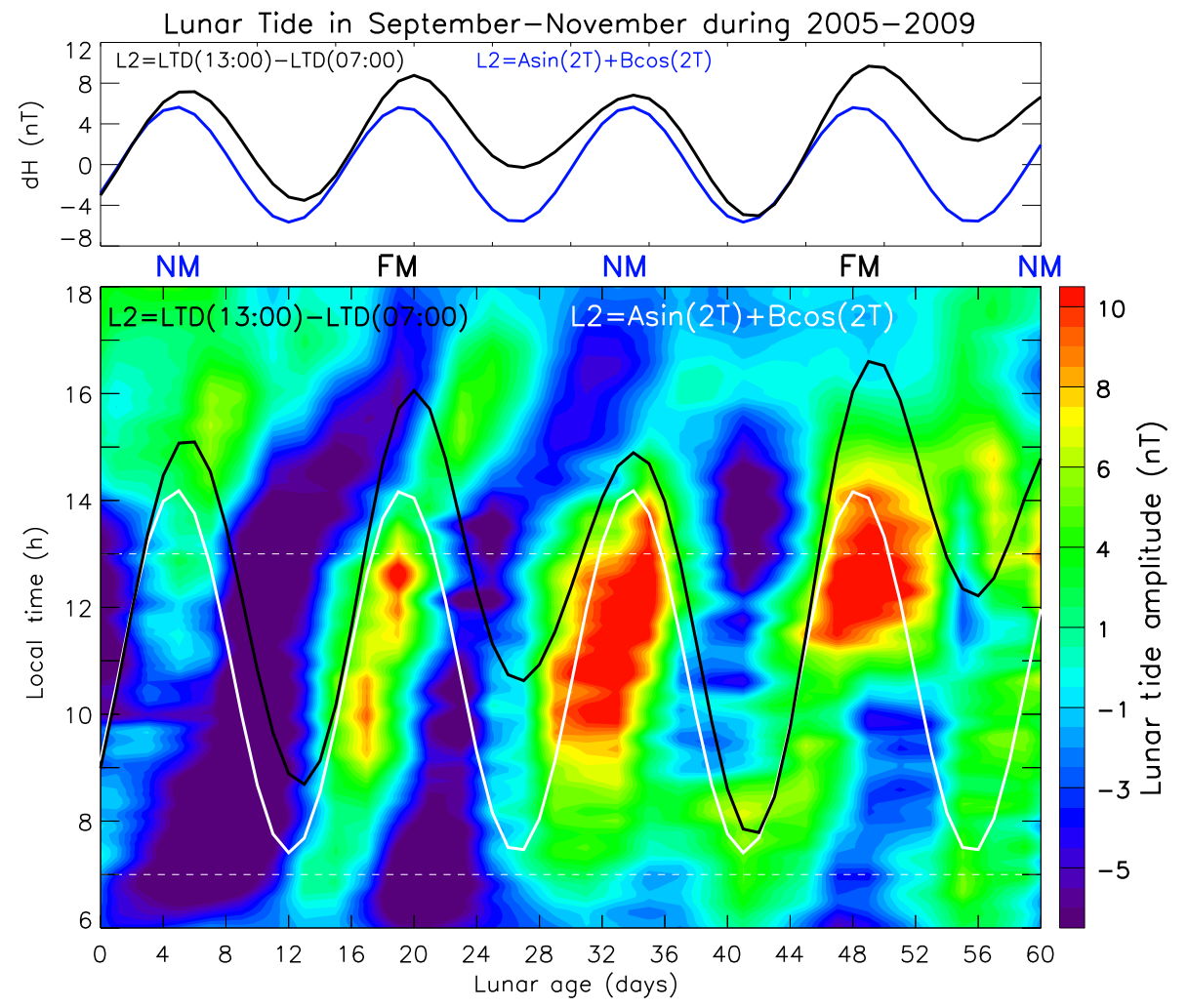

Figure 2. Bottom panel: lunar tides signature on the equatorial electrojet observed at Huancayo during September-November during 20052009. Top panel: the standard component of the lunar tide variation (blue curve) and the difference between the residual extracted at two (13:00 and 07:00) fixed local times (black curve) plotted as a function of lunar age. The acronyms "FM" and "NM" refer to full and new Moon, respectively.

where $\tau$ is the lunar age in days and $A$ and $B$ are coefficients determined using the technique described in (e.g., Winch, 1970; Yamazaki et al., 2012). The top panel (also overplotted in the bottom panel as white curve) in Fig. 2 shows the lunar tide variation (estimated using equation 1) as a function of lunar age. Similarly, the black curves shown in the top and bottom panels represent the difference between the residuals extracted at 13:00 and 07:00 fixed local times. The peak and trough location of the standard semi-diurnal lunar tide amplitude (blue and white curves at the top and bottom panels, respectively) shows excellent one-to-one correspondence with the lunar tide crest and trough extracted from magnetometer observations (black curves) as shown in Fig. 2.

\subsection{Longitudinal variability in the lunar tide}

It has been well documented (England et al., 2006; Lühr et al., 2012; Yizengaw et al., 2014) that the EEJ has a clear longitudinal variability due to several factors, such as geomagnetic field magnitude difference, latitudinal displacement difference in the location of the geomagnetic equator, and nonmigrating tidal signal difference at different longitudes. Similarly, the semi-diurnal lunar tide magnitudes also show visible longitudinal differences. Figure 3 shows the lunar tide signatures on the EEJ, extracted from magnetometers located in the vicinity of the geomagnetic equator at four different longitudinal sectors, mentioned before. The lunar tide residuals are grouped into four seasons (given at the top in blue) and arranged as a function of lunar age. In general, lunar tidal waves are stronger in the American and Asian sectors and weakest in the western African sector. This could be due to the location of the Mbour, which is at higher geomagnetic latitude compared to other stations used for this study. In general, the EEJ reduces as geomagnetic latitude increases, and that results in weaker lunar tide amplitude as it is shown at Mbour in Figs. 3 and 4. Rastogi and Trivedi (1970), using very limited data sets, also reported stronger and weaker lunar tides in the American and Indian sectors, respectively.

The question is, what controls such longitudinal dependence of the lunar tidal waves on the EEJ? As it is stronger during the dayside when the change in the magnetic field or the EEJ is stronger compared to the nightside, the lunar tide may be stronger in the longitudinal sectors where there is a stronger EEJ. Recently, Yizengaw et al. (2014) reported a stronger EEJ in the American and Asian sectors compared to the African sectors, which is consistent with the lunar tide magnitude mentioned above. Another possible factor for longitudinal variability is the non-migrating tidal effect. The 


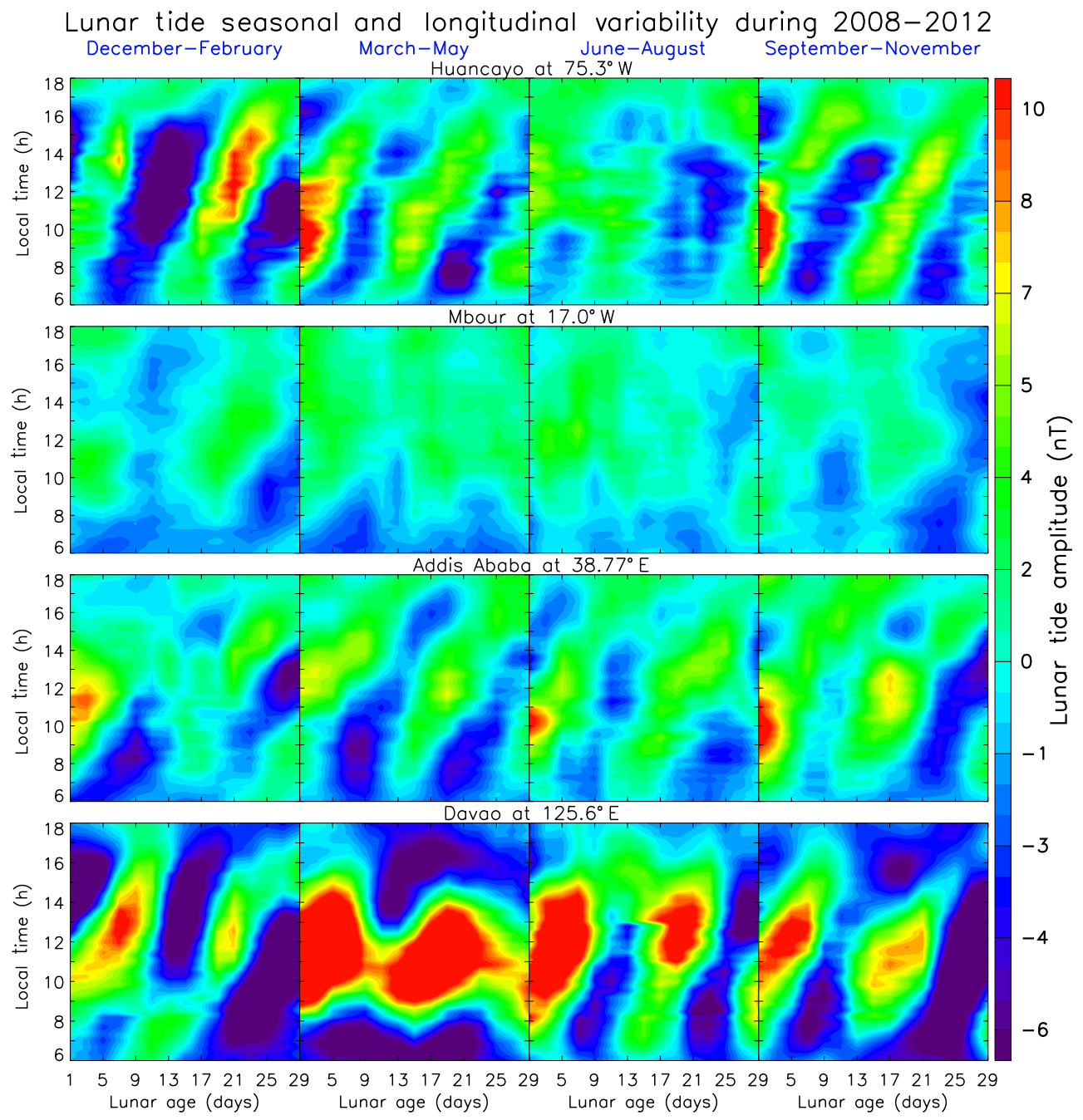

Figure 3. The lunar tide signature on the EEJ detected at different longitudes and seasons. Each panel (from top to bottom) represents different longitudes, as well as (from left right) different seasons. The station name and the corresponding longitude are provided at the top of each panel; similarly, each season is provided in blue at the top.

semi-diurnal non-migrating tides, which are excited by tropospheric latent heat release and propagate into the upper atmosphere (e.g., Hagan and Forbes, 2003), could also have a potential contribution to the longitudinal variability in the lunar tide currents.

\subsection{Seasonal variability in the lunar tide}

Figure 4 shows the 6-year (2005-2010) averaged magnetic field residuals that are rearranged as a function of lunar age for the entire season, revealing the seasonal variability in the lunar tidal impact on the EEJ at four different longitudes. Months of the year (in blue) are also shown at the bottom of each panel. The tidal forces show different seasonal variability at different longitudes but are stronger during January-February at almost all sites. In the American sector (top panel), the lunar tides show stronger amplitudes during Northern Hemisphere winter (December-February) and equinox (October-November and April-May) seasons but weaker during June-July. The lunar tide amplitudes at Mbour (second panel from the top) are generally weaker compared to other longitudinal sectors, and that could be due to the higher geomagnetic latitude location of Mbour as mentioned above. On the other hand, the residuals at Addis Ababa (third panel from the top) show stronger lunar tide amplitude during January-February and in March and September but weaker amplitude in April and December. The residuals at Davao show stronger lunar tide amplitudes during almost the entire year. Since the site experienced significant data gaps (white area), we were not able to see the detailed tidal structure in January and March.

The differences in the distance between the Earth and the Sun contribute in part to the seasonal variation in the lunar tide. The lunar tidal effect is stronger in January at all sites, 

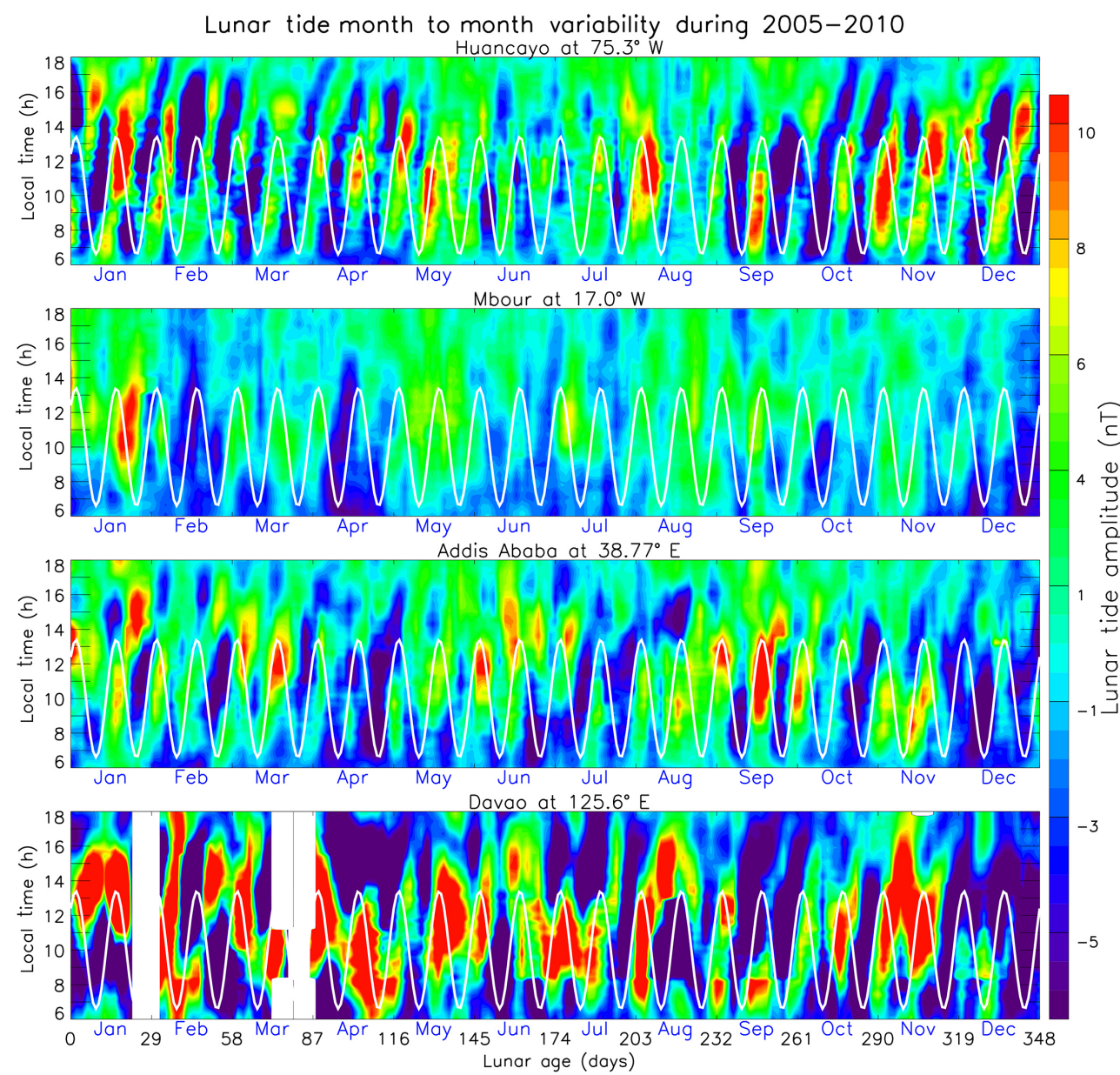

Figure 4. Month-to-month (January-December) variability in the lunar tide influence on EEJ observed at four different longitudes (shown at the top of each panel) over the course of solar minimum period (2005-2010). The overplotted white curves represents the standard component of the lunar tide variation at local noon obtained from Eq. (1), showing quite remarkable agreement with observations performed at four different longitudes.

which is when the Earth is at closest to the Sun (perihelion, occurring around 2 January) (e.g., Thurman, 1994). The tidal wave modulation intensity is proportional to the local ionospheric conductivity. Small annual variations in ionospheric conductivity may arise from annual distance variations between Earth and Sun. Therefore, in January, when the Sun is closer to the Earth, an increased ionization could partly enhance the ionospheric conductivity and consequently the lunar tidal wave amplitude (Schlapp and Malin, 1979). Moreover, January is also the usual time when stratospheric sudden warming (SSW) occurs. It has been widely reported that SSW modify the mean stratospheric temperature and zonal wind conditions, leading to an enhancement of the lunar tide magnitudes (e.g., Fejer et al., 2010; Stening, 2011; Yamazaki et al., 2012; Park et al., 2012). On the other hand, in the absence of a SSW event and when the Earth is at the furthest distance from the Sun (aphelion) during June solstice, the lunar tide influence on the EEJ is very small. However, this interpretation is not supported at all longitudinal sectors.
While the American sector shows weaker tidal amplitude, the eastern African and Asian sectors still show significant tidal amplitudes in June. In particular, in the eastern African sector the lunar tide amplitude becomes stronger at a later local time in June, and weaker in April and December. This suggests that the seasonal variability in lunar tide signatures on the EEJ does not show the same trend of variation at different longitudinal sectors.

Although the lunar tidal force (reported in this study) is for the dayside and ionospheric irregularities are usually a nightside phenomenon, ionospheric irregularities also show similar seasonal variability (not shown in this paper, but previously reported). For example, Hei et al. (2005), using satellite in situ measurements, reported seasonal variability in ionospheric irregularities that revealed very weak irregularities activities in the American sector but stronger and all-year active irregularities in the African sector. Data from recently deployed ground-based stations also showed that the June 

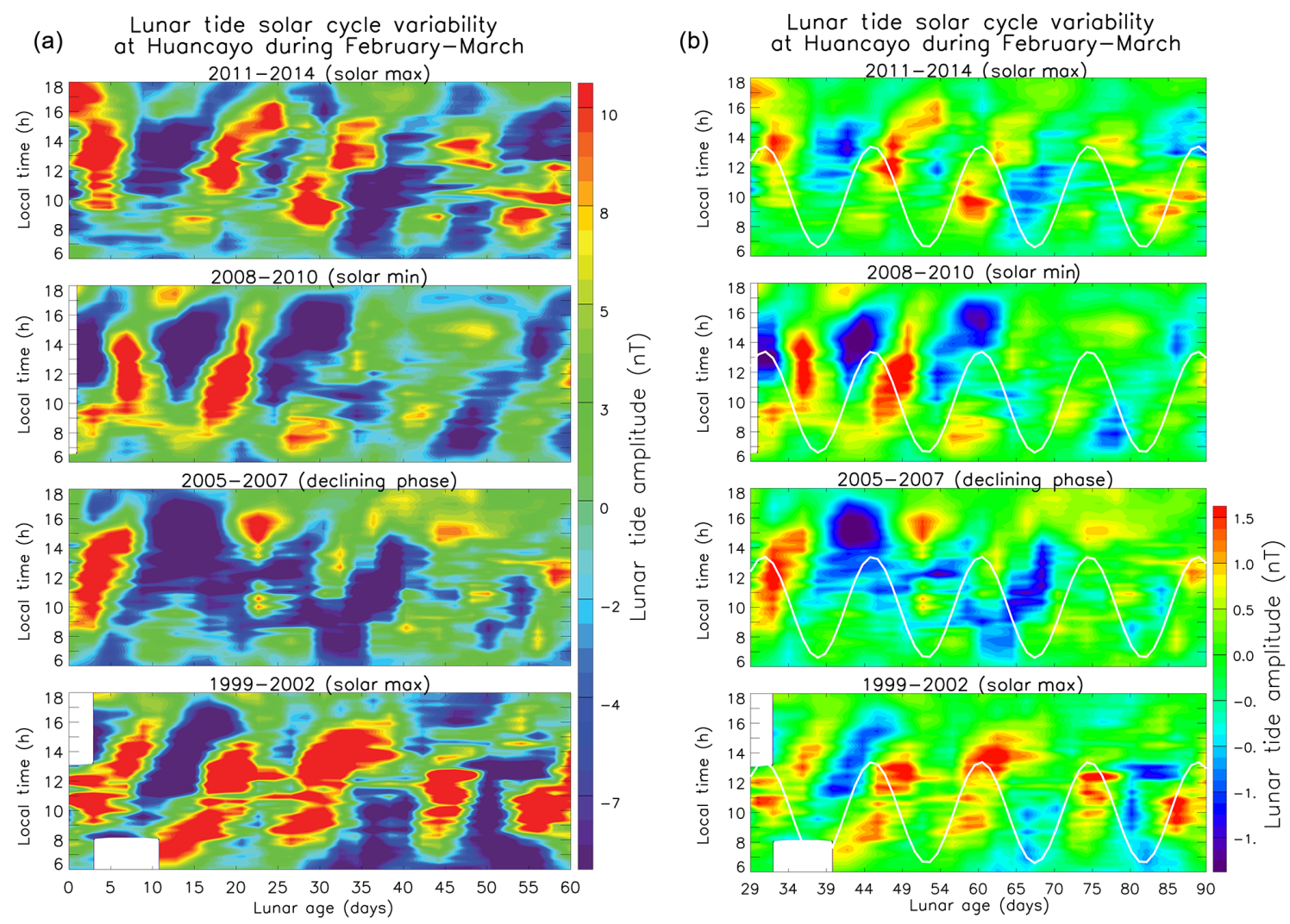

Figure 5. (a) The lunar tidal wave amplitude difference observed at Huancayo during different solar activity periods, which is given at the top of each panel; (b) same format as (a) but for the residuals normalized by the square root of the daily solar radiation.

solstice ionospheric irregularities in the African sectors usually occur at later local times (e.g., Yizengaw et al., 2013).

\subsection{Solar cycle variability in the lunar tide}

In order to identify the solar cycle dependence of the lunar tidal wave strength, we grouped our 17 years of observations into different solar activity conditions. These are from 19992002, 2005-2007, 2008-2010, and 2011-2014, which correspond to maximum, moderate, minimum, and maximum solar cycle conditions, respectively. The data are then arranged as a function of lunar age. Figure 5a shows a typical example of solar cycle variability in the lunar tide signature on the EEJ observed at Huancayo in Peru. Stronger and clear lunar tide signatures are observed during solar maximum periods as shown in the top and bottom panels of Fig. 5a. On the other hand, the magnetic residuals during the moderate (the declining phase in our case) solar activity period do not show a clear lunar tide signature, except during early February (third panel from the top). However, at the time of solar minimum period (second panel from the top), the lunar tides are clearly visible but not as strong as during the solar maximum period, with the exception of the strong tidal amplitude observed in February. The solar cycle variability in the lunar tide signature in the African sectors (figures not shown here) presents slightly different behavior. The lunar tide amplitude difference between solar maximum (2011-2014) and solar minimum (2008-2010) is not that large, because both cases show significantly stronger tidal amplitudes. Due to considerable data gaps experienced during 1999-2002, it was difficult to identify the lunar tide signature amplitude. Similarly, it was impossible to perform solar cycle variability analyses in Davao due to limited data availability (only from 20082012).

It is clear that the change in solar activity may not have a direct significant effect on atmospheric tides in the ionospheric dynamo region (Bremer et al., 1997; Hagan et al., 2001), but the lunar tide amplitude intensification during solar maximum periods could be due to increased ionospheric conductivity. Ionospheric current intensity is dependent not only on the winds that drive the ionospheric dynamo but also on ionospheric conductivity, which depends on the intensity of the ionospheric electron density that is largely influenced by solar activity. We have demonstrated this by normalizing the residuals by the daily value of solar radio emission at $10.7 \mathrm{~cm}$. The daily average value of the observed solar radio emission at $10.7 \mathrm{~cm}$ for each day (F107) and the 81-day-centered average of F107 (F107ADJ) represent the solar cycle variations in the solar radiation (ex- 
treme ultraviolet) that controls ionospheric ionization which is proportional to ionospheric conductivity. We normalized the residuals with the square root of the daily average value of F107 and F107ADJ and rearranged and plotted them in the same format as Fig. 5a. The normalized residuals are presented in Fig. 5b, which shows an identical structure, indicating that the solar cycle variability in lunar tide currents is mostly controlled by ionospheric conductivity. Robinson and Vondrak (1984), using the incoherent-scatter radar at Chatanika in Alaska, found that the height-integrated ionospheric conductivity varies with the square root of the solar flux $(\mathrm{F} 10.7 \mathrm{~cm})$ index. Therefore, because of the mechanism described above, the geomagnetic lunar tide impact on the EEJ varies with solar cycle activity as shown in Fig. 5.

It is also worth pointing out the noticeable lunar tidal wave amplitude difference during new and full Moon periods as shown in Figs. 2-5. It is obvious that the difference in the distance between the Earth and the Moon significantly affects the lunar tidal wave amplitude during the course of a lunar age. Since the Moon has an elliptical orbit around the Earth, the distance between the Earth and Moon varies by about $50000 \mathrm{~km}$ in every lunar month; when the Moon is at the closest (perigee) and farthest (apogee) to the Earth, the tidal forces become stronger (producing above-average ranges) and weaker (less than average) than the usual lunar tidal wave amplitude, respectively. In every 7.5 lunar phase cycles, the perigee distance of the Moon coincides with either a new or full Moon, causing the largest lunar tidal effect (e.g., Heath, 1999).

In conclusion, this study examined the geomagnetic quiet time longitudinal, seasonal, and solar cycle variability in the lunar tide influence on the geomagnetic field variation in the vicinity of the geomagnetic equator. We found that the lunar tidal waves modulate the EEJ current density with significantly different magnitudes at different longitudes, seasons and solar activities. Our results show significant longitudinal variability in the lunar tide signature on the EEJ, stronger in the American and Asian sectors and weaker in the western African sector. In general, the following points can be taken as the main results of this study.

The 17 years of extensive ground-based observations show that the lunar tidal wave influence on equatorial electrodynamics has clear seasonal variability, with inconsistent seasonal behavior between different longitudes, except that all stations experience a strong lunar tide influence in JanuaryFebruary. This clearly has a very similar seasonal behavior to that of the nightside ionospheric density irregularities, not shown here but reported before.

Our results also show a clear solar cycle dependence of the lunar tide signature on the EEJ, which may not be due to the atmospheric tidal changes but to ionospheric conductivity difference that enhances ionospheric currents during solar maximum periods (compared to solar minimum periods).
Data availability. The magnetometer data from AAE, HUA, and MBO stations used for this study can be accessed from the INTERMAGNET public online database at http://www.intermagnet.org/. The magnetic data from DVO station have been obtained from the Magnetic Data Acquisition System (MAGDAS) database, which is archived at the International Center for Space Weather Science and Education (ICSWSE) website (http://magdas.serc.kyushu-u.ac.jp/ request/index.html), upon request from the project leader of MAGDAS, A. Yoshikawa (e-mail address: yoshi@geo.kyushu-u-ac.jp). The Dst index can be found from the USGS Geomagnetism Program public database (https://geomag.usgs.gov/).

Competing interests. The authors declare that they have no conflict of interest.

Acknowledgements. This work has been supported by NASA LWS (NNX11AP02G), AFOSR (FA9550-12-1-0437 and FA9550-15-1-0399), and NSF (AGS1450512) grants. Part of Brett A. Carter's work was supported by Australian Research Council (LP130100243) grants and the Victorian Postdoctoral Fellowship awarded to Brett A. Carter. The authors are indebted to the INTERMAGNET and USGS teams for the magnetometer data resources and Dst index, respectively.

The topical editor, C. Stolle, thanks F. Conte and one anonymous referee for help in evaluating this paper.

\section{References}

Anderson, D., Anghel, A., Yumoto, K., Ishitsuka, M., and Kudeki, E.: Estimating daytime vertical ExB drift velocities in the equatorial F-region using ground-based magnetometer observations, Geophys. Res. Lett., 29, 1596, doi:10.1029/2001GL014562, 2002.

Bartels, J. and Johnston, H. F.: Geomagnetic tides in horizontal intensity at Huancayo, Part I, terrestrial magnetism and atmospheric electricity, J. Geophys. Res., 45, 269-308, 1940.

Bremer, J., Schminder, R., Greisiger, K. M., Hoffmann, P., Kürschner, D., and Singer, W.: Solar cycle dependence and longterm trends in the wind field of the mesosphere/lower thermosphere, J. Atmos. Sol. Terr. Phys., 61, 765-774, 1997.

Chapman, S.: The solar and lunar diurnal variations of terrestrial magnetism, Philos. T. R. Soc. Lond., 218, 1-118, 1919.

Chapman, S. and Lindzen, R.: Atmospheric Tides, Reidel, Dordrecht, Holland, 66-105, 1970.

Chau, J. L., Fejer, B. G., and Goncharenko, L. P.: Quiet variability of equatorial $E \times B$ drifts during a stratospheric warming event, Geophys. Res. Lett., 36, L05101, doi:10.1029/2008GL036785, 2009.

England, S. L., Maus, S., Immel, T. L., and Mende, S. B.: Longitude variation of the E-region electric fields caused by atmospheric tides, Geophys. Res. Lett., 33, L21105, doi:10.1029/2006GL027465, 2006.

Fejer, B. G., Olson, M. E., Chau, J. L., Stolle, C., Lühr, H., Goncharenko, L. P., Yumoto, K., and Nagatsuma, T.: Lunardependent equatorial ionospheric electrodynamic effects during 
sudden stratospheric warming, J. Geophys. Res., 115, A00G03, doi:10.1029/2010JA015273, 2010.

Fejer, B. G., Tracy, B. D., Olson, M. E., and Chau, J. L.: Enhanced lunar semi-diurnal equatorial vertical plasma drifts during sudden stratospheric warmings, Geophys. Res. Lett., 38, L21104, doi:10.1029/2011GL049788, 2011.

Hagan, M. E. and Forbes, J. M.: Migrating and nonmigrating semi-diurnal tides in the upper atmosphere excited by tropospheric latent heat release, J. Geophys. Res., 108, 1062, doi:10.1029/2002JA009466, 2003.

Hagan, M. E., Roble, R. G., and Hackney, J.: Migrating thermospheric tides, J. Geophys. Res., 106, 12739-12752, doi:10.1029/2000JA000344, 2001.

Heath, R.: Sun, Moon and Earth, Bloomsbury Publishing USA, 1999.

Hei, M. A., Heelis, R. A., and McClure, J. P.: Seasonal and longitudinal variation of large-scale topside equatorial plasma depletions, J. Geophys. Res., 110, A12315, doi:10.1029/2005JA011153, 2005.

Lühr, H., Siddiqui, T. A., and Maus, S.: Global characteristics of the lunar tidal modulation of the equatorial electrojet derived from CHAMP observations, Ann. Geophys., 30, 527-536, doi:10.5194/angeo-30-527-2012, 2012.

Matsushita, S.: Solar quiet and lunar daily variation fields, in: Physics of Geomagnetic Phenomena, edited by: Matsushita, S. and Campbell, W. H., Academic, New York, 301-424, 1967.

Matsushita, S.: Solar and lunar tidal effects on the low-latitude ionosphere - A review, J. Atmos. Terr. Phys., 35, 1027-1034, 1973.

Matsushita, S. and Campbell, W. H.: Lunar semi-diurnal variations of the geomagnetic field determined from the 2 min data scaling, J. Atmos. Terr. Phys., 34, 1187-1200, 1972.

Park, J., Lühr, H., Kunze, M., Fejer, B. G., and Min, K. W.: Effect of sudden stratospheric warming on lunar tidal modulation of the equatorial electrojet, J. Geophys. Res., 117, A03306, doi:10.1029/2011JA017351, 2012.

Rastogi, R. G.: Lunar tidal oscillations in $\mathrm{H}$ at Huancayo during IGY/IGC, Ann. Geophys., 24, 779-788, 1968.
Rastogi, R. G. and Trivedi, N. B.: Luni-solar tides in $H$ at stations within the equatorial electrojet, Planet. Space Sci., 18, 367-377, 1970.

Richmond, A. D. and Roble, R. G.: Electrodynamic effects of thermospheric winds from the NCAR thermospheric general circulation model, J. Geophys. Res., 92, 12365-12376, 1987.

Robinson, R. M. and Vondrak, R. R.: Measurements of E region ionization and conductivity produced by solar illumination at high latitudes, J. Geophys. Res., 89, 3951-3958, 1984.

Sawada, R.: The atmospheric lunar tides and the temperature profile in the upper atmosphere, Geophys. Mag., 27, 636-643, 1956.

Schlapp, D. M. and Malin, S. R. C.: Some features of the seasonal variation of geomagnetic lunar tides, Geophys. J. Inter., 59, 161170, 1979.

Stening, R. J.: Lunar tide in the equatorial electrojet in relation to stratospheric warmings, J. Geophys. Res., 116, A12315, doi:10.1029/2011JA017047, 2011.

Tarpley, J. D.: The ionospheric wind dynamo-I* lunar tide, Planet. Space Sci., 18, 1075-1090, 1970.

Tarpley, J. D. and Balsley, B. B.: Lunar variations in the Peruvian electrojet, J. Geophys. Res., 77, 1951-1960, 1972.

Thurman, H. V.: Introductory Oceanography, seventh edition, New York, NY, Macmillan, 252-276, 1994.

Winch, D. E.: Geomagnetic Lunar Tides, $\mathrm{O}_{1}$ Component, J. Geom. Geoelect., 22, 319-328, 1970.

Yamazaki, Y., Yumoto, K., Uozumi, T., and Cardinal, M. G.: Intensity variations of the equivalent $\mathrm{S}_{q}$ current system along the $210^{\circ}$ magnetic meridian, J. Geophys. Res., 116, A10308, doi:10.1029/2011JA016632, 2011.

Yamazaki, Y., Richmond, A. D., and Yumoto, K.: Stratospheric warmings and the geomagnetic lunar tide: 1958-2007, J. Geophys. Res., 117, A04301, doi:10.1029/2012JA017514, 2012.

Yizengaw, E., Retterer, J., Pacheco, E. E., Roddy, P., Groves, K., Caton, R., and Baki, P.: Post-midnight Bubbles and Scintillations in the Quiet-Time June Solstice, Geophys. Res. Lett., 40, doi:10.1002/2013GL058307, 2013.

Yizengaw, E., Moldwin, M. B., Zesta, E., Biouele, C. M., Damtie, B., Mebrahtu, A., Rabiu, B., Valladares, C. F., and Stoneback, R.: The longitudinal variability of equatorial electrojet and vertical drift velocity in the African and American sectors, Ann. Geophys., 32, 231-238, doi:10.5194/angeo-32-231-2014, 2014. 